\title{
Localized amyloidosis of the epididymis: a previously unreported phenomenon
}

\author{
Lucio Díaz-Flores ${ }^{1 *} \mathbb{D}$, Ricardo Gutiérrez ${ }^{1}$, Ma. del Pino García², Manuel Jose Gayoso³, Jose Luis Carrasco ${ }^{1}$, \\ Lucio Díaz-Flores Jr ${ }^{1}$ and Hugo Álvarez-Argüelles ${ }^{1}$
}

\begin{abstract}
Background: Localized amyloidosis has not been documented in the epididymis; we report this phenomenon for the first time.

Case presentation: The first aim of this work is to report three cases of localized epididymal amyloidosis. Two cases were clinically detected as epididymal nodules, and a third after reviewing 120 epididymides obtained with neighbouring pathological processes. Amyloid deposits showed Congo red positivity, with yellow-green birefringence, and immunohistochemical expression for light chains kappa and lambda, transthyretin, amyloid $P$ and cytokeratin AE1 AE3. No immunoreactivity for amyloid A was seen. Amyloid deposit location was intraluminal, with partial or total loss of the epididymal epithelium and subsequent passage to the interstitium, forming large masses. No amyloid deposits were observed around blood vessels. A secondary objective was to explore in normal epididymis the amyloid tested in epididymal amyloidosis. In normal epididymides, expression of amyloid $\mathrm{P}$ and transthyretin was detected in the apical surface of epithelial cells. Amyloid $\mathrm{P}$ also showed strong expression in spermatozoa.
\end{abstract}

Conclusion: We contribute the existence of localized epididymal amyloidosis, which presents a distinctive, initial intratubular location, where there is a unique proteome and where functional amyloids act during sperm maturation.

Keywords: Epididymis, Amyloid, Amyloidosis

\section{Background}

In anatomical regions of the male reproductive system that contribute to the transport, maturation and/or required fluid medium of spermatozoa, localized amyloidosis has been pointed out in seminal vesicles, vasa deferentia and ejaculatory ducts [1-9]. The objective of this work is to report localized amyloidosis in the epididymis for the first time. In addition, we study the following: a) amyloid deposit distribution in the epididymis, to assess where the deposits are formed and $b$ ) the presence in normal epididymides of the amyloids tested in our cases of epididymal amyloidosis. Our observations indicate that epididymal amyloidosis is organ-limited, with a distinctive initial location (intratubular).

\footnotetext{
* Correspondence: kayto54@gmail.com

${ }^{1}$ Department of Basic Medical Sciences, Faculty of Medicine, University of La Laguna, Ofra-La Cuesta, s/n, La Laguna, 38071 Tenerife, Islas Canarias, Spain

Full list of author information is available at the end of the article
}

\section{Case presentation}

After observing two cases (Cases 1 and 2) of pseudotumoral epididymal amyloidosis, epididymides (n: 120) were examined for the presence of pathologic amyloid deposits and for amyloid detection. A new case (Case 3) of subclinical amyloidosis was obtained in this review. All patients were Caucasian, and the relevant findings of the cases are shown in Table 1. Evidence of systemic amyloidosis, paraproteinemia, or underlying plasma cell dyscrasia was not demonstrated. Finally, the amyloids tested in epididymal amyloidosis were also checked in seven normal epididymides. The study was carried out in accordance with the code of ethics of the World Medical Association.

Histologic sections were stained with Haemotoxylin and Eosin (H\&E), Congo red, Periodic Acid-Schiff (PAS) and Wilder's reticulin stain. After Congo red staining, the sections were also viewed under polarized light. 
Table 1 Characteristics of reported cases and antibodies used for immunohistochemistry

\begin{tabular}{|c|c|c|c|c|c|c|c|}
\hline Case & $\begin{array}{l}\text { Age } \\
\text { (years) }\end{array}$ & Presentation and resulting diagnosis & Larger diameter $(\mathrm{cm})$ & $\begin{array}{l}\text { Contralateral } \\
\text { epididymal } \\
\text { exploration }\end{array}$ & Operation & $\begin{array}{l}\text { Follow-up } \\
\text { (months) }\end{array}$ & $\begin{array}{l}\text { IHC } \\
\text { Primary antibodies } \\
\text { used }\end{array}$ \\
\hline 1 & 77 & $\begin{array}{l}\text { Nodule in the left epididymis } \\
\text { Result: Epididymal amyloidosis }\end{array}$ & 1.4 & Thickened & Nodule removal & $\begin{array}{l}48 \\
\text { (Free of disease) }\end{array}$ & $\begin{array}{l}\text { Light chain } \lambda \\
\text { Dako [D: } 1: 50]\end{array}$ \\
\hline 2 & 72 & $\begin{array}{l}\text { Nodule in the right epididymis } \\
\text { Result: Epididymal amyloidosis }\end{array}$ & 1.6 & NED & Nodule removal & $\begin{array}{l}9 \\
\text { (Free of disease) }\end{array}$ & $\begin{array}{l}\text { Light chain } \mathrm{K} \\
\text { Dako [D: } 1: 50] \\
\text { Transthyretin }\end{array}$ \\
\hline 3 & 67 & $\begin{array}{l}\text { Left scrotal swelling for } 4 \text { years. } \\
\text { Physical examination: a firm, } \\
\text { non-reducible mass. } \\
\text { Result: Paratesticular liposarcoma } \\
\text { and Epididymal amyloidosis } \\
\text { without tumour involvement }\end{array}$ & $\begin{array}{l}0.7 \\
\text { (size refers only } \\
\text { to epididymal } \\
\text { amyloidosis) }\end{array}$ & NA & Radical Orchiectomy & NA & $\begin{array}{l}\text { Dako [D: 1:600] } \\
\text { Amyloid P } \\
\text { Abcam [D: 1:50] } \\
\text { Amyloid A } \\
\text { Dako [D: 1:50] } \\
\text { CK AE1 AE3 } \\
\text { Dako [D: 1:100] } \\
\text { EMA } \\
\text { Dako [D: 1:100] } \\
\text { CD68 } \\
\text { Dako [D: 1:100] } \\
\text { CD34 } \\
\text { Dako [D: 1:50] } \\
\text { aSMA } \\
\text { Dako [D: 1:50] }\end{array}$ \\
\hline
\end{tabular}

IHC Immunohistochemistry, NED No evidence of disease, NA Not available, CK Cytokeratin, EMA Epithelial membrane antigen

Immunohistochemical study included the primary antibodies listed in Table 1.

\section{Results}

\section{General characteristics of epididymal amyloidosis}

In cases 1 and 2 of epididymal amyloidosis, the surgically removed nodules were firm, yellowish grey in colour, and 1.4 and $1.6 \mathrm{~cm}$ in size, respectively. Case 3 (obtained after the microscopic review of 120 epididymides) showed a larger diameter of $0.7 \mathrm{~cm}$ (Table 1).

In $H \& E$ stained sections, amorphous hyaline eosinophilic deposits were observed (Fig. 1a). The deposits showed Congo red positivity (Fig. 1b), with yellow-green birefringence under polarized light (Fig. 1c), and irregular PAS positivity. Immunohistochemical expression of transthyretin (Fig. 2a), light chains kappa (Fig. 2b) and lambda (Fig. 2c), and amyloid P (Fig. 2d) was observed. Pan cytokeratin (CK) AE1 AE3 also showed irregular positivity in the amyloid deposits (Fig. 2e). There was no immunoreactivity for amyloid A, and no amyloid deposits were seen in blood vessel walls. Spermatozoa were absent.

\section{Distribution of amyloid deposits}

Amyloid deposits were observed in the lumen of the convoluted epididymal tubule and in several lumps in the interstitium (Figs. 1a and 2a to c), showing similar immunohistochemical expression in both locations. On occasion, several separate aggregates of amyloid deposits were organized in a similar convoluted path to that of the epididymis (Fig. 2c).

The distribution and quantity of intratubular amyloid bodies varied depending on the section of the tubule.
Thus, they were scarce and free in the lumen of some tubular sections of the epididymis, but numerous in others, where they were densely grouped, obliterating and distending the epididymal lumen (Figs. $1 \mathrm{a}$ and $2 \mathrm{a}$ to $\mathrm{c}$ ). The free bodies in the lumen showed Congo red positivity (Fig. 2f), with immunofluorescence under polarized light (Fig. 2g) and amyloid P expression (Fig. 2h), and were associated with other materials, including vesicles, particles, filaments and small dense bodies. Intraluminal CD68+ macrophages (Fig. 2i) were also observed with intracytoplasmic PAS+ granules (Fig. 2j), which expressed transthyretin and amyloid P (Fig. 2k, corresponding to amyloid P).

The interstitial amyloid deposits formed aggregates, ranging from small to large interstitial masses (Figs. 1a, $\mathrm{b}$ and $2 \mathrm{a}$ to $\mathrm{c})$.

\section{Relationship between intratubular and interstitial amyloid deposits}

Frequently, the luminal and interstitial deposits were in continuity and were therefore partially lined by epithelium (Fig. 3a), which showed pan CK AE1 AE3 and epithelial membrane antigen (EMA) expression. Residual epithelial bands were even observed on the surface of larger interstitial deposits (Fig. 2e). The intratubular and interstitial zones in these confluent deposits were not only differentiated by the presence or absence of epithelial coating, but also by the existence of other components within the deposits. A reticulin network, and CD34+ and/or aSMA + stromal cells were observed in interstitial but not in luminal zones of the deposits (Fig. 3b, corresponding to the reticulin network). Moreover, epithelial folds with degenerative phenomena surrounded occasionally 


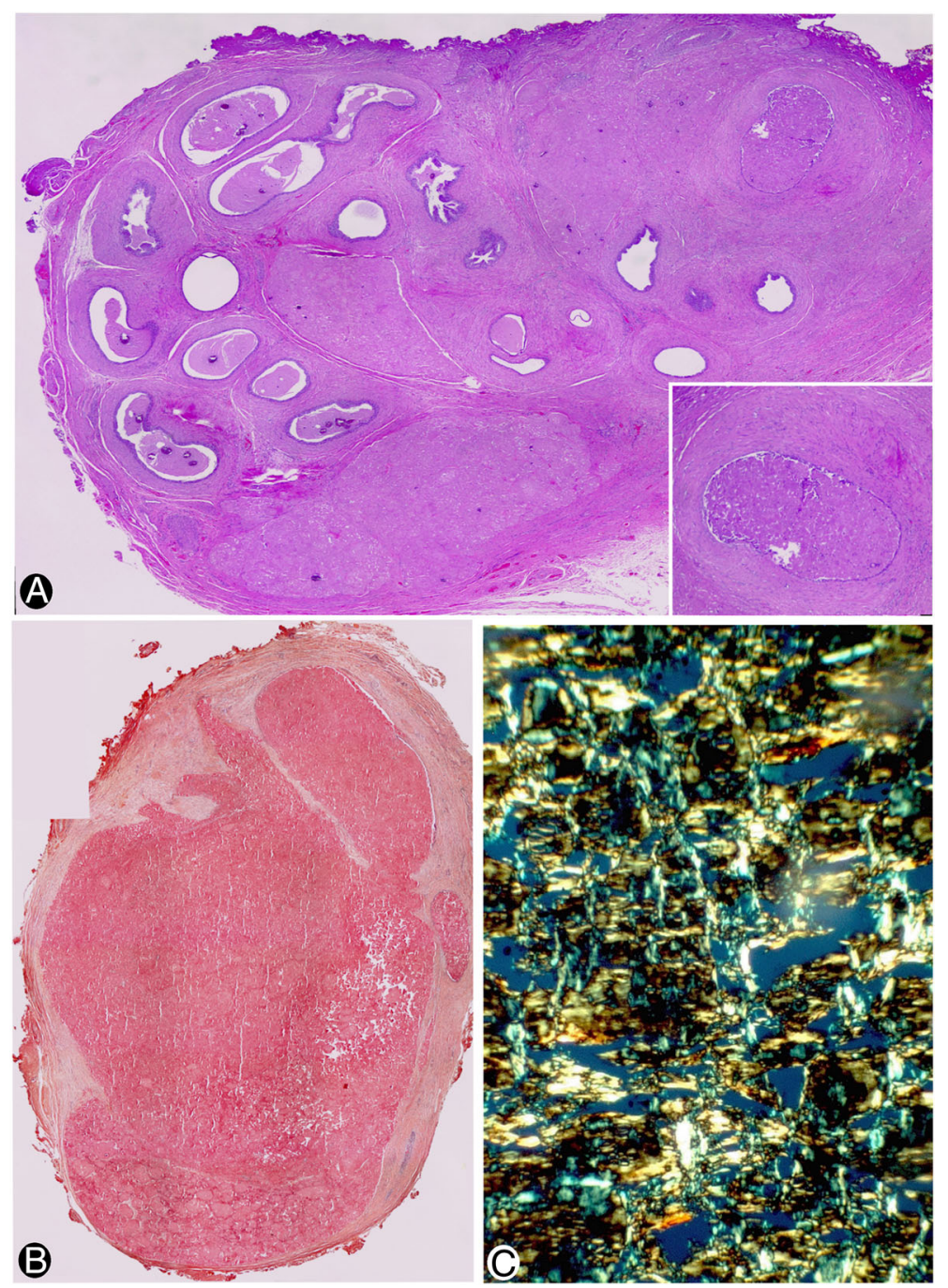

Fig. 1 Amyloid deposits in the epididymes. a Eosinophilic amyloid deposits are observed in an H\&E stained section. Insert: a zone of deposits in the epididymal lumen. $\mathbf{b}$ Congo red positivity. $\mathbf{c}$ Yellow-green birefringence under polarized light. a corresponds to case 1 , and $\mathbf{b}$ and $\mathbf{c}$ to case 2 . $\mathbf{a}$ and $\mathbf{b}: \times 10$ (insert in $\mathrm{A}: \times 20) . \mathbf{c}: \times 120$

portions of intraluminal amyloid deposits, which were partially incorporated in the interstitium (Fig. 3c to e).

\section{Detection of amyloids (with tested expression in epididymal amyloidosis) in normal epididymides} In the epididymides surgically obtained from neighbouring pathologic processes, transthyretin (Fig. 3f) and amyloid P (Fig. 3g) were expressed in the apical surface of the epithelium. Amyloid P also showed strong expression in spermatozoa (Fig. $3 \mathrm{~g}$ and h). Occasional macrophages with PAS and amyloid P positive bodies were seen.

\section{Discussion}

We report three cases of localized amyloidosis in the epididymis, two clinically detected as a nodular mass and the other obtained together with a neighbouring pathologic process (para-testicular liposarcoma). Although localized amyloidosis has been described in several locations of the male reproductive system, which contribute to the transport, maturation and/or required fluid medium of spermatozoa [1-9], to the best of our knowledge, this is the first description of localized epididymal amyloidosis. Awareness of the existence of epididymal amyloidosis and of its presentation as small nodules in the epididymis, as well as knowledge of its histopathology, is of interest in clinical and pathological differential diagnoses, including tumours. Moreover, the characteristics of the lesion support the initial development of amyloid deposits in the epididymal lumen, where a specific proteome occurs [10-12], and non-pathological functional amyloids and mechanisms of protein aggregation control take place [13-15]. Below, we examine these issues. 

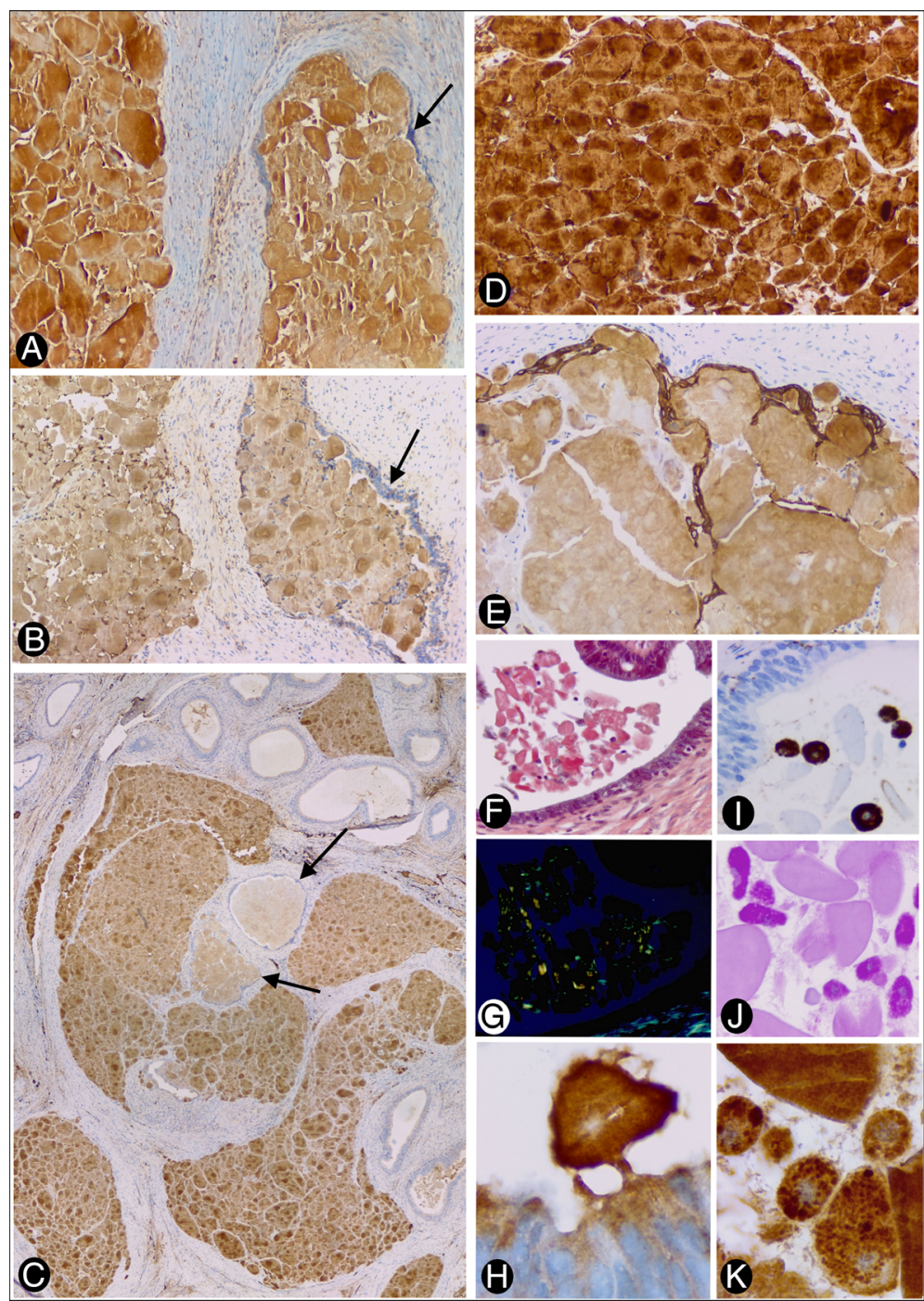

Fig. 2 Immunohistochemical expression and distribution of amyloid deposits (a to $\mathbf{e}$ ), and characteristics of free bodies and macrophages in other regions of the epididymal lumen (f to $\mathbf{k}$ ). Expression in the amyloid deposits of transthyretin (a), light chain kappa (b) and lambda (c), amyloid P (d) and pan CK AE1 AE3 (e) is observed. Note the presence of epithelium-lined (arrows) (intraluminal) and non-epithelium-lined (interstitial) amyloid deposits. In C, the intraluminal and interstitial deposits are organized in a similar convoluted path to that of the epididymal tubule. In E, residual pan CK AE1 AE3+ epithelial cell bands persist in the periphery of the interstitial deposits. In other regions of the epididymal lumen, free amyloid bodies in the lumen associated with vesicles, particles and filaments are present ( $\mathbf{f}$ to $\mathbf{h}$ ). Note Congo red positivity (f) with yellow-green birefringence $(\mathbf{g})$ and immunohistochemical expression of amyloid P (h). Intraluminal CD68 positive macrophages (i) showing PAS positive intracytoplasmic granules (j), which express amyloid $\mathbf{P}(\mathbf{k})$, are also observed. $\mathbf{a}, \mathbf{b}, \mathbf{d}$ and $\mathbf{e}$ correspond to case 2 . $\mathbf{c}$ and $\mathbf{f}$ to $\mathbf{k}$ correspond to case 3 . a, b, d and $\mathbf{e}: \times 120, \mathbf{c}: \times 10, \mathbf{f}, \mathbf{g}, \mathbf{I}$ and $\mathbf{j}: \times 320$, $\mathbf{h}$ and $\mathbf{k}: \times 480$

Our cases were seen in patients aged 67 and over. Although this type of amyloidosis could be regarded as a senile form, larger series are needed to confirm this possibility.

Our observations indicate an initial deposit of amyloid in the epididymal lumen, with subsequent passage to the interstitium. The findings that support this sequence are as follows: a) densely grouped deposits in some sections of the epididymis occupy both the lumen and the interstitium, after distention of the epididymal lumen and partial epithelial disruption, b) presence of epithelial folds with degenerative phenomena, surrounding portions of intraluminal amyloid deposits, which are partially incorporated in the interstitium, c) epithelial strips remain on the surface of some large interstitial amyloid masses, d) several distinct aggregates of amyloid deposits are organized in a similar convoluted path to that of the epididymis, and e) the deposits occupying both the interstitium and the lumen appear with and without reticulin networks and/or stromal cells, respectively. 

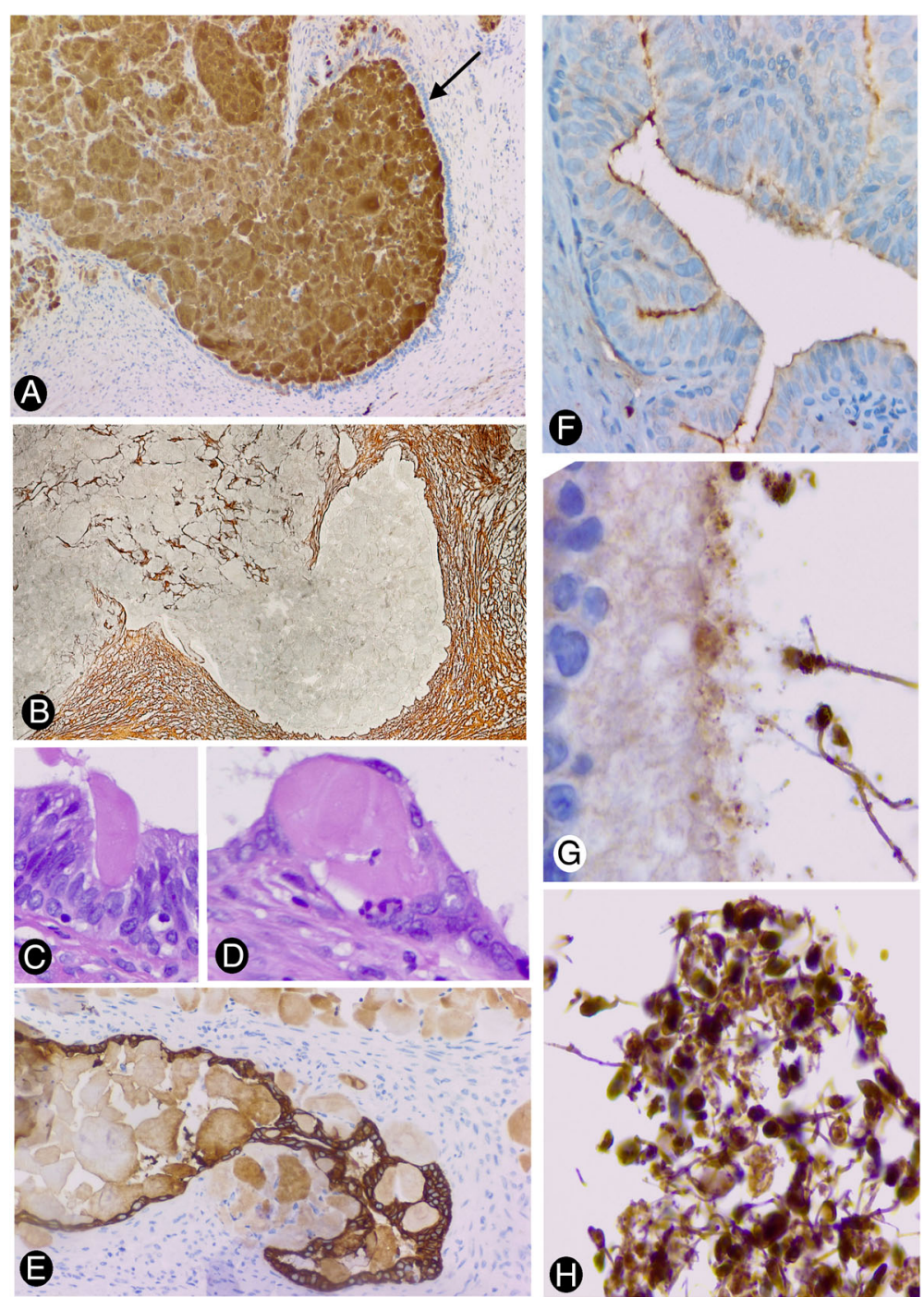

Fig. 3 Relationship between intratubular and interstitial amyloid deposits (a to $\mathbf{d}$ ), and detection of amyloids in normal epididymis (e to $\mathbf{g}$ ). a: Epithelium-lined (arrow) (intraluminal) and non-epithelium-lined (interstitial) zones of an amyloid deposit are observed in continuity. b: A reticulin network in the interstitial zone but not in the luminal zone of the amyloid deposit is observed. c to e: Epithelial folds with degenerative phenomena are observed surrounding small portions of intraluminal amyloid deposits, which are partially incorporated in the interstitium. In normal epididymis, expression of transthyretin ( $\mathbf{f})$ and amyloid $\mathbf{P}(\mathbf{g})$ is observed in the apical surface of the epididymal epithelium. Strong expression of amyloid $\mathrm{P}$ is also shown in spermatozoa ( $\mathbf{g}$ and $\mathbf{h}$ ). $\mathbf{a}$ : transthyretin immunostaining. $\mathbf{c}$ and $\mathbf{d}$ : H\&E staining. e: pan CK AE1 AE.immunostaining. $\mathbf{a}, \mathbf{b}$, e and $\mathbf{f}: \times 120$; $\mathbf{c}$ and $\mathbf{d}: \times 320 ; \mathbf{g}$ and $\mathbf{h}: \times 340$

Both intraluminal and interstitial deposits in the epididymis show amyloid characteristics, including positivity for Congo red with yellow-green birefringence under polarized light. In our observations, apparent negativity for amyloid A, any evidence of systemic amyloidosis, paraproteinemia or underlying plasma cell dyscrasia, and the absence of amyloid deposits involving vascular walls support an organ-limited deposition of heterogeneous amyloids, including light chains $\mathrm{k}$ and $\lambda$, and transthyretin. Amyloid P was also present. However, our immunohistochemical results were obtained in paraffin-embedded tissue blocks, and amyloid deposits can contain several misfolded proteins. Therefore, a more specific characterization of the proteome and misfolded proteins requires further study (see below).

The onset of amyloid deposits in the epididymal lumen may be related to our results showing amyloid P (involved in the deposition, stabilization and persistence of amyloid) and transthyretin (a transport protein in the serum and cerebrospinal fluid) expression in the apical surface of the normal epithelial cells of the epididymis. Moreover, amyloid P showed strong immunoreactivity in the spermatozoa, which concurs with the observations of others authors [16]. Likewise, immunoreactivity for 
pan CK AE1 AE3 also concurs with the presence of keratins in the sperm proteome [17].

The comparison with amyloidosis described in other locations of the male reproductive system that contribute to the transport, maturation and/or required fluid medium of spermatozoa, mainly seminal vesicles, indicates that the deposits have a different location: initially intraluminal with subsequent passage to the interstitium in the epididymis, and predominantly sub-epithelial in the seminal vesicles [1-9], as occurs in choroid plexus amyloidogenic papillomas [18]. The mechanisms to explain these differences in the polarization of the deposits require further studies. Likewise, the positive reaction for light-chain antibodies has been reported for several cases of localized amyloidosis in the urogenital tract $[19,20]$, and the expression of light chains $\mathrm{K}$ and/or $\lambda$ in localized amyloidosis in other regions is not exceptionally rare [21].

The unique and distinctive location of amyloid deposits in the epididymal lumen, with subsequent passage to the interstitium, could depend on the peculiar functions of this anatomical region, in which proteomic studies show the more sequentially modified milieu of the body [10-12]. Indeed, the epididymis actively participates in the maturation, protection and acquisition of motility and fertility of spermatozoa by synthesis, secretion and post-transitional modifications of important molecules, including a high concentration of several hundred proteins, most of which are actively secreted by the epididymal epithelium (for review, see [12]). Spermatozoa are dependent on this extracellular environment, since their DNA is highly compacted, making processes of transcription and translation impossible [22-24]. Epididymosomes (vesicles present in the epididymis) are involved in the acquisition of new sperm proteins during epididymal transit [22-24]. Some of these proteins may form functional amyloids, and in vitro studies have shown amyloid formation in this unique milieu. Thus, this milieu comprises cystatin-related epididymal spermatogenic members (CRES), which pass from monomeric forms in the proximal caput region to an aggregated amyloid state in the distal caput region $[15,25]$, and amyloidogenic prion protein is present in epididymosomes and associated with hydrophobic proteins in lipophilic complex [26-28]. Likewise, concentration of luminal content occurs in the epididymis (more than $90 \%$ of the fluid is removed from the epididymis) [29], facilitating macromolecular crowding, and protein misfolding and aggregation. However, in the epididymis, amyloids act without causing pathology, due to the mechanisms of extracellular quality control [13, 14, 25]. This control includes: a) ubiquitin-dependent proteolysis (classically considered as an intracellular quality control system and currently as also having extracellular functionality in sperm quality control) [30], b) chaperones (involved in the prevention of protein aggregation), since chaperone clusterin is found in soluble high molecular mass lipophilic complex present in the lumen of the epididymis during sperm maturation (around 30\% of total epididymal secretion [11]), and c) transglutaminase, which prevents the formation of amyloid-type aggregates of CRES in the epididymis by post-translational modifications (transglutaminase cross-linking of cystatin CRES - [25]). Therefore, the onset of amyloidosis deposits in the lumen of the epididymis, with subsequent passage to the interstitium, suggests a disturbance of the mechanisms mentioned above, mainly of extracellular (intraluminal) functional amyloid control.

While intracellular, post-translational quality control systems to repair or remove misfolded proteins have been well studied, extracellular mechanisms of folding control of secreted proteins are not well described, except in the lumen of the epididymis [13, 14]. These mechanisms in the epididymis have been considered highly significant for understanding the misfolded protein formation involved in some pathological processes, including Alzheimer's disease, cerebral angiopathies, and type II diabetes [13, 14]. In this way, amyloid deposits in the epididymis may provide a substrate to explore not only the alteration of the reproductive function, but also the mechanism of extracellular protein misfolding control in several diseases. Thus, new studies in epididymal amyloidosis are required to explore the functional amyloids outlined above and the molecules that act in their extracellular quality control.

\section{Conclusion}

We describe the presence of localized amyloidosis in the epididymis for the first time. The initial intraluminal formation is particularly interesting because it may also be the pathological expression of amyloid in an anatomical region with critical functions during sperm maturation, including the uniqueness of the human epididymal proteome and several molecular pathways, such as those involved in specific intraluminal functional amyloids and their quality control.

\footnotetext{
Acknowledgements

The authors would like to thank Kim Eddy for the English revision.

Funding

There is no any financial support for this work.

Availability of data and materials

Data sharing not applicable to this article as no datasets were generated or analyzed during the current study.

Authors' contributions

LD-F, RG and MPG participated in the histopathological evaluation, performed the literature review, acquired the photomicrographs and contributed to conception and design. MJG, JLC, LD-F Jr. and HA-A performed the immunohistochemical stain evaluation and revised the manuscript. All the authors read and approved the final manuscript.
} 


\section{Authors' information}

Not applicable.

\section{Ethics approval and consent to participate}

Ethical approval for this study was obtained from Ethical Committee of La Laguna University (No. CEIBA2017-0250).

\section{Consent for publication}

Informed consent was obtained from the patients for publication.

\section{Competing interests}

The authors declare that they have no competing interests.

\section{Publisher's Note}

Springer Nature remains neutral with regard to jurisdictional claims in published maps and institutional affiliations.

\section{Author details}

${ }^{1}$ Department of Basic Medical Sciences, Faculty of Medicine, University of La Laguna, Ofra-La Cuesta, s/n, La Laguna, 38071 Tenerife, Islas Canarias, Spain. ${ }^{2}$ Department of Pathology, Hospiten ${ }^{\circledast}$ Hospitals, Tenerife, Spain. ${ }^{3}$ Department of Cell Biology and Pharmacology, Faculty of Medicine, University of Valladolid, Valladolid, Spain.

Received: 12 April 2017 Accepted: 18 July 2017

\section{Published online: 04 August 2017}

\section{References}

1. Argon A, Sımşır A, Sarsik B, Tuna B, Yörükoğlu K, Nıflığlu GG, Sen S Amyloidosis of seminal vesicles; incidence and pathologic characteristics. Turk Patoloji Derg. 2012;28:44. doi:10.5146/tjpath.2012.01096.

2. Coyne JD, Kealy WF. Seminal vesicle amyloidosis: morphological, histochemical and immunohistochemical observations. Histopathology. 1993;22:173.

3. Furuya S, Masumori N, Furuya R, Tsukamoto T, Isomura H, Tamakawa M. Characterization of localized seminal vesicle amyloidosis causing hemospermia: an analysis using immunohistochemistry and magnetic resonance imaging. J Urol. 2005;173:1273.

4. Jun SY, Kim KR, Cho KS, Ro JY. Localized amyloidosis of seminal vesicle and vas deferens: report of two cases. J Korean Med Sci. 2003;18:447.

5. Kee KH, Lee MJ, Shen SS, Suh JH, Lee OJ, Cho HY, Ayala AG, Ro JY. Amyloidosis of seminal vesicles ejaculatory ducts: a histologic analysis of 21 cases among 447 prostatectomy specimens. Ann Diagn Pathol. 2008;12:235. doi: 10.1016/j.anndiagpath.2007.12.004.

6. Pitkänen P, Westermark P, Cornwell GG 3rd, Murdoch W. Amyloid of the seminal vesicles. A distinctive and common localized form of senile amyloidosis. Am J Pathol. 1983:110:64

7. Seidman JD, Shmookler BM, Connolly B, Lack EE. Localized amyloidosis of seminal vesicles: report of three cases in surgically obtained material. Mod Pathol. 1989;2:671.

8. Süess K, Moch H, Epper R, Koller A, Dürmüller U, Mihatsch MJ. Heterogeneity of seminal vesicle amyloid. Immunohistochemical detection of lactoferrin and amyloid of the prealbumin-transthyretin type. Pathologe. 1998;19:115.

9. Yang Z, Laird A, Monaghan A, Seywright M, Ahmad I, Leung HY. Incidental seminal vesicle amyloidosis observed in diagnostic prostate biopsies-are routine investigations for systemic amyloidosis warranted? Asian J Androl. 2013;15:149. doi:10.1038/aja.2012.125.

10. Dacheux JL, Belleannée C, Jones R, Labas V, Belghazi M, Guyonnet B, Druart X, Gatti JL, Dacheux F. Mammalian epididymal proteome. Mol Cell Endocrinol. 2009;306:45. doi:10.1016/.mce.2009.03.007.

11. Dacheux JL, Dacheux F. New insights into epididymal function in relation to sperm maturation. Reproduction. 2014;147:R27-42. doi:10.1530/REP-13-0420.

12. Dacheux JL, Dacheux F, Druart X. Epididymal protein markers and fertility. Anim Reprod Sci. 2016;169:76. doi:10.1016/j.anireprosci.2016.02.034.

13. Cornwall GA, von Horsten HH, Swartz D, Johnson S, Chau K, Whelly S. Extracellular quality control in the epididymis. Asian J Androl. 2007;9:500-7. doi:10.1111/j.1745-7262.2007.00309.x.

14. Cornwall GA. Role of posttranslational protein modifications in epididymal sperm maturation and extracellular quality control. Adv Exp Med Biol. 2014; 759:159. doi:10.1007/978-1-4939-0817-2_8
15. Whelly S, Muthusubramanian A, Powell J, Johnson S, Hastert MC, Cornwall GA. Cystatin-related epididymal spermatogenic subgroup members are part of an amyloid matrix and associated with extracellular vesicles in the mouse epididymal lumen. Mol Hum Reprod. 2016;22:729-44. doi:10.1093/molehr/ gaw049.

16. Malm J, Sonesson A, Hellman J, Bjartell A, Frohm B, Hillarp A. The pentraxin serum amyloid $\mathrm{P}$ component is found in the male genital tract and attached to spermatozoa. Int J Androl. 2008;31:508. doi:10.1111/j.1365-2605.2007.00800.x.

17. Skerget $\mathrm{S}$, Rosenow MA, Petritis K, Karr TL. Sperm proteome maturation in the mouse Epididymis. PLoS One. 2015;10(11):e0140650. doi:10.1371/journal. pone.0140650. eCollection 2015

18. Díaz-Flores L, Gutiérrez R, Madrid JF, Alvarez-Argüelles H, Valladares F, Spreafico M, Díaz-Flores L Jr. Choroid plexus papilloma with stromal deposition of amyloid and elastic material. Amyloid. 2010;17:69. doi:10.3109/ 13506129.2010 .483117

19. Monge M, Chauveau D, Cordonnier C, Noël LH, Presne C, Makdassi R, Jauréguy M, Lecaque C, Renou M, Grünfeld JP, Choukroun G. Localized amyloidosis of the genitourinary tract: report of 5 new cases and review of the literature. Medicine (Baltimore). 2011;90:212. doi:10.1097/MD. Ob013e31821cbdab.

20. Zhou F, Lee P, Zhou M, Melamed J, Deng FM. Primary localized amyloidosis of the urinary tract frequently mimics neoplasia: a clinicopathologic analysis of 11 cases. Am J Clin Exp Urol. 2014;2:71. eCollection 2014

21. Westermark P. Localized AL amyloidosis: a suicidal neoplasm? Ups J Med Sci. 2012;117:244. doi:10.3109/03009734.2012.654861.

22. Sullivan R, Frenette G, Girouard J. Epididymosomes are involved in the acquisition of new sperm proteins during epididymal transit. Asian J Androl. 2007;9:483. doi:10.1111/j.1745-7262.2007.00281.x.

23. Sullivan R, Saez F. Epididymosomes, prostasomes, and liposomes: their roles in mammalian male reproductive physiology. Reproduction. 2013;146:R21-35. doi:10.1530/REP-13-0058.

24. Sullivan R. Epididymosomes: role of extracellular microvesicles in sperm maturation. Front Biosci (Schol Ed). 2016:8:106-14

25. von Horsten HH, Johnson SS, SanFrancisco SK, Hastert MC, Whelly SM, Cornwall GA. Oligomerization and transglutaminase cross-linking of the cystatin CRES in the mouse epididymal lumen: potential mechanism of extracellular quality control. J Biol Chem. 2007;282:32912. doi:10.1074/jbc. M703956200

26. Ecroyd H, Sarradin P, Dacheux JL, Gatti JL. Compartmentalization of prion isoforms within the reproductive tract of the ram. Biol Reprod. 2004;71:993. doi:10.1095/biolreprod.104.029801.

27. Ecroyd H, Belghazi M, Dacheux JL, Gatti JL. The epididymal soluble prion protein forms a high-molecular-mass complex in association with hydrophobic proteins. Biochem J. 2005:392:211. doi:10.1042/BJ20050459.

28. Gatti JL, Métayer S, Moudjou M, Andréoletti O, Lantier F, Dacheux JL, Sarradin P. Prion protein is secreted in soluble forms in the epididymal fluid and proteolytically processed and transported in seminal plasma. Biol Reprod. 2002;67:393.

29. Mann T, Lutwak-Mann C. Passage of chemicals into human and animal semen: mechanisms and significance. Crit Rev Toxicol. 1982;11:1. doi:10. 3109/10408448209089846.

30. Sutovsky P. Ubiquitin-dependent proteolysis in mammalian spermatogenesis, fertilization, and sperm quality control: killing three birds with one stone. Microsc Res Tech. 2003;61:88. doi:10.1002/jemt.10319.

\section{Submit your next manuscript to BioMed Central and we will help you at every step:}

- We accept pre-submission inquiries

- Our selector tool helps you to find the most relevant journal

- We provide round the clock customer support

- Convenient online submission

- Thorough peer review

- Inclusion in PubMed and all major indexing services

- Maximum visibility for your research

Submit your manuscript at www.biomedcentral.com/submit
Biomed Central 